\title{
UMA PERSPECTIVA DOS GESTORES E HÓSPEDES DA HOTELARIA DE PEQUENO E MÉDIO PORTE DE ARACAJU-SE
}

\author{
Rafaela Santana Oliveira ${ }^{1}$ \\ Marlyana Dias Nascimento ${ }^{1}$ \\ Matheus Pereira Mattos Felizola ${ }^{2}$
}

RESUMO: O presente trabalho fez parte de um projeto vinculado à Pró-reitoria de Extensão e Assuntos Comunitários da Universidade Federal de Sergipe (PROEX/UFS) e procurou agregar teoria a prática de forma gradual e dinâmica. Diante da importância do marketing para os empreendimentos hoteleiros, foram realizadas duas pesquisas, ambas utilizaram como instrumento entrevistas semiestruturadas com os gestores e hóspedes de 25 organizações hoteleiras de pequeno e médio porte em Aracaju-SE. Os resultados foram apresentados em forma de palestras destinadas aos gestores e colaboradores dos hotéis entrevistados. Foi aplicada uma série de orientações para contribuir com o aprimoramento das ações de marketing como: construção, atualização e monitoramento de mídias sociais, capacitação de profissionais e contratação de profissionais especializados.

PALAVRAS-CHAVE: Turismo. Hotelaria. Marketing. Comportamento de consumo.

\section{A perspective of managers and guests of small and medium hotels in Aracaju, Sergipe state}

\begin{abstract}
This paper, which is part of a project of the Pro-Rectorate of Extension and Community Affairs of the Federal University of Sergipe (PROEX/UFS), aimed to add theory to practice in a gradual and dynamic way. Given the importance of marketing for hotel developments, two researches were carried out. Both of them conducted semi-structured interviews with managers and guests from 25 small and medium hotel organizations in Aracaju, Sergipe state. The results were presented in lectures given to the managers and employees of the hotels that attended the interview. A set of guidelines were applied aiming to contribute to the improvement of marketing actions, such as: social media building, updating and monitoring; professional training and recruitment of specialized employees.
\end{abstract}

KEYWORDS: Tourism. Hotel-management. Marketing. Consumer behavior.

\section{INTRODUÇÃO}

O turismo é um importante setor que movimenta a economia brasileira. O trade turístico é um conjunto de empreendimentos que compõe o produto turístico. Dentre esses empreendimentos, encontra-se a hotelaria, que consiste na acomodação de pessoas, sejam elas turistas ou excursionistas em outra cidade, estado ou país. Grande parte dessas empresas é formada pelos

\footnotetext{
Graduandas em Comunicação Social (Habilitação em Publicidade e Propaganda) na Universidade Federal de Sergipe (raphaela-oliver@ hotmail.com; marlyana@hotmail.com).

2 Doutor em Ciências Sociais pela Universidade Federal do Rio Grande do Norte, professor no curso de Comunicação Social da Universidade Federal de Sergipe (matheus.felizola.marketing@gmail.com). 
pequenos e médios empreendimentos que necessitam de estratégias de marketing para o alcance do êxito empresarial. O marketing, por meio de seu conjunto de ações, visa proporcionar a satisfação dos consumidores e realizar seus desejos. No âmbito hoteleiro, essa satisfação torna-se uma tarefa difícil, já que se trata de sonhos, pois viagens são idealizadas e sonhadas na mente das pessoas.

A hotelaria de pequeno e médio porte da capital sergipana foi analisada por duas pesquisas que apresentaram um panorama das ações de marketing desenvolvidas nesse porte de empreendimento, mostrando a visão e o perfil dos hóspedes dessas organizações. Ambas as pesquisas foram usadas como subsídio para a elaboração de duas palestras, objetivando apresentar os resultados dessas pesquisas e orientar gestores e colaboradores dos hotéis entrevistados, prestando serviço à sociedade hoteleira local.

\title{
Turismo
}

A atividade turística passa por um processo de crescimento e, nos últimos anos, vem se desenvolvendo e se modernizando constantemente em vários setores, com o surgimento de novas e diferenciadas redes.

\begin{abstract}
Denominado de indústria de viagens, integrada pelo conjunto de empresas que prestam seus serviços ao "setor", ou seja, pelas empresas de transporte em todas as suas modalidades, estabelecimentos de hospedagem, agências que alugam automóveis, agências de viagens e outras, define o turismo para seus próprios fins específicos: o turismo como o negócio de prover e comercializar serviços e facilidades para o prazer dos viajantes, logo está diretamente relacionado com os governos, transportadores, alojamentos, restaurantes e indústrias de entretenimento e, indireta e virtualmente, com toda a indústria e negócios no mundo. (ACERENZA, 2002, p. 41).
\end{abstract}

Em relação à integridade e ao conjunto de empresas estabelecido, é esse elo que sustenta essa "indústria de viagens", por exemplo, se o governo ou alguma transportadora falhar, o viajante não atingirá um alto grau de satisfação.

Principalmente quando se utiliza o serviço de marketing turístico, é importante perceber seu crescimento e melhora com o desenvolvimento eficiente das ferramentas de análise eacompanhamento de mercado para melhor compreender o seu consumidor, e, com isso, suprir suas necessidades e, principalmente, realizar seus desejos. Quando se trata de turismo, o target possui os mais variados desejos e, a partir daí, é necessário segmentar o mercado, procurando sempre satisfazê-lo.

Assim, é fundamental que o turismo, desde a base da sua administração, no caso do setor hoteleiro, até o seu topo, assegure uma coesão em toda a sua cadeia estrutural empresarial, proporcionando, assim, uma equipe estruturada e preparada para a recepção e a excelência no tratamento do cliente. Uma característica que se agrega à formação do colaborador é o domínio de um ou mais idiomas 
estrangeiros, o que garante uma melhor reverência com os visitantes, turistas e excursionistas ${ }^{3}$.

\title{
Marketing turístico e hotelaria
}

O marketing turístico sempre foi fundamental ao sucesso de lugares ou organizações. Entende-se por marketing turístico o conjunto de ações aplicadas em prol do êxito de lugares ou empreendimentos turísticos. Segundo a definição dePhilip Kotler(2000a, p. 18), "éum conjunto de atividades que facilita a realização de troca entre os diversos agentes que atuam diretamente no mercado de produtos turísticos".

Esse conceito, para outros autores, é considerado genérico demais. Barreto Filho apresenta um conceito mais amplo sobre o assunto, como podemos observar:

\begin{abstract}
O marketing turístico envolve as ações no mercado turístico que visam atender com produtos turísticos as necessidades dos consumidores, procurando satisfazer os seus desejos e construir uma perfeita relação de trocas. Assim, as organizações precisam corresponder às necessidades dos turistas (SANTOS apud BARRETO FILHO, 1999, p. 22).
\end{abstract}

Nessa acepção, marketing envolve analisar as necessidades do consumidor, garantir informações precisas para desenhar ou produzir produtos ou serviços que estão de acordo com as expectativas do consumidor, satisfazer suas preferências e também criar e manter relacionamentos com os consumidores e fornecedores. Neste sentido, outra definição importante é a de Boone e Kurtz (2009, p. 8), para os quais marketing consiste no "processo de planejar e executar a concepção, a fixação de preço, a promoção e a distribuição de ideias, produtos, serviços, organizações e eventos para criar e manter relacionamentos que satisfaçam objetivos individuais e organizacionais".

O cliente é base da hotelaria. Quando há mudanças na composição dos hóspedes, como alterações econômicas sociais e culturais, os hotéis ou pousadas são obrigados a mudar suas estratégias para adequar-se ao seu público-alvo.

A hotelaria vai muito além de satisfazer a necessidade dos consumidores, ela tem o papel de concretizar sonhos e provocar desejos em suas mentes. Assim, a segmentação de mercado exerce um papel preponderante para o sucesso das ações de marketing na hotelaria. Segundo Kotler (1998, p. 225), "a segmentação de mercado representa um esforço para um aumento de precisão de alvo de uma empresa. Ela pode ser adotada em quatro níveis: segmentos, nichos, áreas locais e indivíduos".

Quando o empreendimento não direciona suas ações para determinado público, ele perde o foco, já que as segmentações servem para direcionar o conteúdo apropriado para o target com o qual se quer comunicar. Cobra (2005, p. 238) apresenta um conceito de público-alvo voltado ao turismo:

\footnotetext{
3 Para Acerenza (2002, p. 40-41), "visitante quer dizer, para fins estatísticos, qualquer pessoa que visita um país diferente do de sua residência habitual, por razões diversas da de exercer uma ocupação remunerada no país visitado; em contrapartida o termo turista significa o visitante que permanece pelo menos vinte e quatro horas no país visitado e cujos motivos da viagem podem ser: descanso (recreação, férias, saúde, religião e esporte), negócios, familiares, missão oficial, reuniões. Já o termo excursionista são visitantes temporários cuja permanência não ultrapassa as vinte e quatro horas no país visitado (compreende os viajantes em cruzeiros)".

Em Extensão, Uberlândia, v. 13, n. 1, p. 113-120, jan. / jun. 2014. 
Toda comunicação em turismo deve ser direcionada para um público [...] com essa definição, dita em marketing de público-alvo, é preciso saber o que esse público quer e a partir dá configurar o produto. Uma vez concebido o serviço de turismo, é importante escolher a mensagem que fale as expectativas e fantasias das pessoas.

Muitos hotéis optam por segmentos como público corporativo, turistas de lazer, dentre outros. Diante desse contexto, necessita-se identificar os canais de comunicação mais adequados para atingir o públicoalvo com eficácia em sua comunicação.

\section{Turismo e hotelaria em Aracaju-SE}

Em Aracaju-SE, o turismo se destaca, principalmente, no âmbito do lazer e dos negócios, e é constituído por turistas em torno dos 34 anos e provindos da Região Nordeste, geralmente do Estado da Bahia, como foi retratado no instrumento de pesquisa aplicado.

Oliveira (2012), no trabalho intitulado “As Ações de Marketing nas Pequenas e Médias Empresas do Setor Hoteleiro em Aracaju" observou que "o turismo da capital sergipana é voltado para os negócios de curto prazo, geralmente três dias, e os turistas vêm principalmente da Bahia." Nesse sentido, podese perceber que o turista para negócio passa no local apenas o tempo necessário, considerado curto, para usufruir da sua atividade profissional e que, a sua maioria, provém do estado vizinho, devido à proximidade com Aracaju e a cidade propiciar campos em certas áreas que satisfazem esses targets.

A capital sergipana se destaca por conter um litoral de longa extensão e praias com variadas utilidades em relação a atrativos de lazer. A aventura do desconhecido e do exótico combina com as atividades de diversão, porém, a paisagem litorânea do local, por si só, já é considerada um enorme atrativo, com potencial de uso para a recreação e o turismo em si.

Segundo o site do Brasilturis Journal ${ }^{4}$, aproximadamente $46 \%$ dos turistas que visitam Aracaju são baianos e, pensando nisso, a Secretaria de Estado do Turismo (Setur) e a Empresa Sergipana de Turismo realizaram ações em Salvador-BA, mostrando que o foco do Estado de Sergipe é de âmbito nacional, com um direcionamento especial para o turismo baiano.

\section{METODOLOGIA}

O trabalho teve como método inicial uma revisão bibliográfica sobre os temas que envolvem o marketing turístico. Posteriormente, foram realizadas duas pesquisas qualitativas e quantitativas de caráter exploratório. Uma delas foi realizada com gestores por meio de entrevistas pessoais semiestruturadas compostas por 29 questões abertas e fechadas, visando conhecer as ações desenvolvidas na hotelaria de pequeno e médio porte em Aracaju-SE.

\footnotetext{
${ }^{4}$ Cf. $<$ http://www.brasilturis.com.br/>.
} 
A cidade, segundo dados da EMSETUR (Empresa Sergipana de Turismo) ${ }^{5}$, possui 126 empresas do setor hoteleiro. Para a pesquisa, a amostra foi 25 empreendimentos, que variaram entre hotéis e pousadas, correspondendo a aproximadamente $20 \%$ deste universo. A amostra foi sugerida por gestores (muitas vezes proprietários dos hotéis) ou diretores de marketing das organizações classificadas em pequeno e médio porte.

A outra pesquisa buscou conhecer a visão dos hóspedes sobre as organizações pesquisadas, contabilizando 68 entrevistados. Também foram feitas entrevistas pessoais semiestruturadas com hóspedes aleatórios dos hotéis e pousadas da amostra. O roteiro contou com 17 questões fechadas e 1 aberta. Dentre outras perguntas, destacam-se: o motivo pela escolha do hotel ou pousada, se o custo-benefício foi atingido, o diferencial do estabelecimento, o meio de divulgação que conheceu o hotel ou pousada, o tempo de estadia.

A partir dos resultados das pesquisas realizadas com os gestores e hóspedes, foram elaboradas duas palestras distintas, nas quais foram apresentados os dados das pesquisas e algumas sugestões para os gestores e colaboradores.

\section{RESULTADOS}

A internet encontra-se cada vez mais presente no setor hoteleiro de Aracaju. As reservas atualmente são feitas, em sua grande maioria, online, como afirmaram $92 \%$ dos entrevistados, e $68 \%$ dos hotéis e pousadas pesquisados mantêm parcerias com portais de reservas, como booking.com, decolar.com, hotéis.com, dentre outros.

Nota-se a presença de alguns profissionais fluentes em mais de uma língua, geralmente os próprios empreendedores ou seus filhos, que trabalham na administração. A pesquisa mostrou que $50 \%$ domina o inglês e o espanhol; $25 \%$, somente inglês; $8 \%$, inglês, espanhol e italiano; $8 \%$, inglês e italiano; e 9\% domina o espanhol e o italiano.

A maioria dos pequenos e médios empreendimentos hoteleiros de Aracaju não realiza uma análise de mercado concorrente, apenas $24 \%$ afirma realizar pesquisa de concorrência, sendo $83 \%$ delas informais, geralmente, por meio de contato direto entre os gerentes mais próximos, e apenas $17 \%$ formais.

Quanto ao meio de divulgação mais visualizado pelos hóspedes, o destaque foi para a internet com $76 \%$, mostrando, cada vez mais, a importância dessa ferramenta no desempenho do empreendimento no mercado.

Um diferencial de extrema importância para os consumidores no momento de sua estadia é o atendimento da recepção, com 53\% declarando esse fator como predominante, em termos de serviço. Isso mostra o quanto a capacitação de gerentes e funcionários é importante e necessária para o destaque e evolução da organização e da gestão hoteleira.

\footnotetext{
${ }^{5}$ Cf. $<$ http://br.kekanto.com/biz/emsetur-empresa-sergipana-de-turismo $>$.
} 


\section{A capacitação}

O projeto iniciou por uma base teórica bastante densa referente ao marketing turístico e ao funcionamento de serviços de hotelaria, para que, a partir das análises com as leituras propostas, fosse possível elaborar o tema para os artigos e segmentá-lo de forma coerente.

A partir das decisões temáticas e agendadas as datas para as visitas nos hotéis e pousadas de AracajuSE, foi necessário a elaboração de um piloto referente aos questionários, que seriam aplicados aos gestores ou gerentes de marketing das organizações e aos hóspedes dos locais escolhidos.

Com base nos resultados das pesquisas, na análise de dados e na tabulação dos questionários, a partir do referencial teórico estudado, foram redigidos dois artigos científicos que tratam do marketing turístico, cada um sob uma perspectiva: as ações empregadas pelos gestores e a visão dos hóspedes sobre os empreendimentos de pequeno e médio porte de Aracaju. Feito isso, organizou-se a capacitação, em dois encontros, voltada para os responsáveis pelo marketing nos estabelecimentos e também para os clientes.

O primeiro encontro foi somente com os gestores das organizações entrevistadas, no qual, inicialmente, lhes foram apresentadas as apurações da pesquisa e seus resultados. Em seguida, houve um momento para as dicas e sugestões e, logo após, um espaço para perguntas, visando uma maior interação.

O segundo dia de evento contou com o mesmo cronograma de apresentação, diferenciando-se apenas o público: colaboradores dos hotéis e pousadas. Adiscussão focou as perspectivas dos hóspedes sobre as empresas. Buscou-se mostrar a importância do colaborador para o êxito das ações de marketing, já que não adianta investir em propaganda para atrair uma quantidade considerável de hóspedes se o fator de peso na escolha de um serviço e fidelização de clientes é a experiência positiva com o atendimento.

Foto 1 - Palestra desenvolvida para os colaboradores dos hotéis e pousadas de pequeno e médio porte de Aracaju-SE.

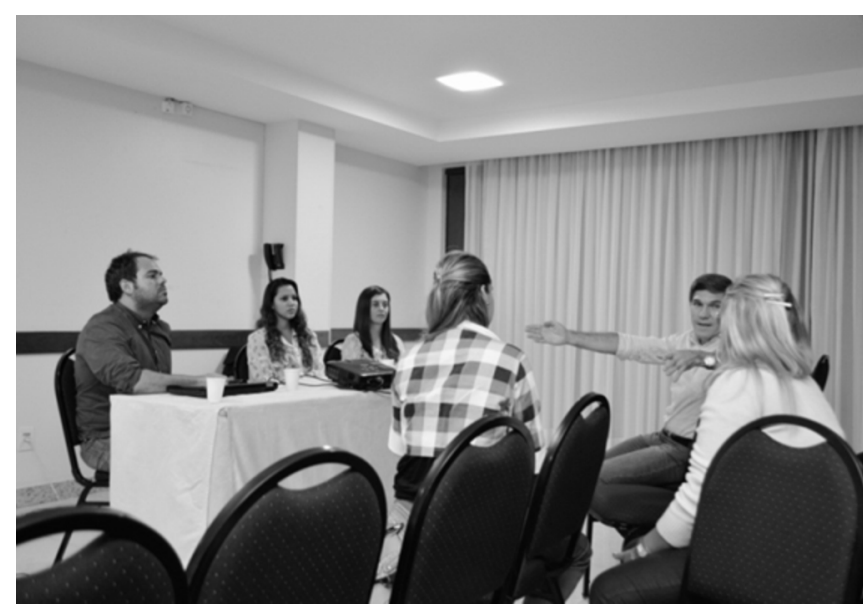

Fonte: Vanessa Silva Menezes. 
Nas duas palestras, houve um direcionamento especial para internet, pelo fato de as pesquisas realizadas terem demonstrado ser o meio mais utilizado na comunicação, tanto para vendas quanto para divulgação. As mídias sociais tiveram destaque nas apresentações, pois elas apresentam ser meios baratos e eficazes de promover uma marca e fazê-la interagir com o target.

\section{CONSIDERAÇÕES FINAIS}

Diante da importância do marketing para o setor hoteleiro e suas contribuições para o êxito das organizações, pode-se observar o quanto as pequenas e médias empresas da hotelaria dependem de suas ferramentas. E Aracaju é uma capital composta, em sua maioria, por empreendimentos hoteleiros de pequeno e médio porte.

As pesquisas demonstraram que as empresas dispõem de um capital restrito para aplicação de ações de marketing, como no âmbito da comunicação, por exemplo. O mesmo motivo impede essas organizações de realizarem pesquisa para segmentar o seu público e investirem em ações de endomarketing, ausentando-se também de cursos e palestras de capacitação. Diante desse contexto, resta-lhes apenas a internet como principal meio de vendas e comunicação praticamente todas as ações são realizadas por meio dela - o que lhe garantiu um foco especial nas palestras realizadas para os gestores e colaboradores.

Os hóspedes apontaram, como elemento diferencial na experiência do serviço, o atendimento, constatando também a falta de profissionais com domínio em outra língua, argumentos que levaram à construção de uma palestra específica para os colaboradores da área de atendimento.

As palestras agregaram teoria à prática. Por meio do referencial teórico e dos dados primários obtidos mediante as duas pesquisas realizadas, obteve-se um panorama das ações implementadas pelos gestores e o perfil dos hóspedes desses empreendimentos. Isso foi fundamental para a elaboração das palestras e para o repasse de dicas aos gestores e colaboradores, contribuindo, assim, com a proposta da prestação de serviço à comunidade hoteleira de pequeno e médio porte da capital sergipana.

Outro ponto que merece ser destacado é a interdisciplinaridade do projeto, que agregou conhecimentos de marketing, turismo, hotelaria e comunicação, contribuindo para o desenvolvimento científico na área de comunicação, auxiliando, assim, a sociedade hoteleira de pequeno e médio porte a compreender os fenômenos mercadológicos ao seu redor e aplicar ações de marketing para o sucesso de suas organizações.

\section{REFERÊNCIAS}

ACERENZA, M. A. Administração do turismo: conceituação e organização. Bauru: EDUSC, 2002.

AÇÕES do governo estimulam a vinda de turistas para Sergipe. Brasilturis Jornal, São Paulo, 15 
maio 2013. Disponível em: $<$ http://www.brasilturis.com.br/noticias.php?id=9848\&noticia=acoesdo-governo-estimulam-a-vinda-de-turistas-par>. Acesso em: 17 mar. 2014.

BOONE, L.; KURTZ, D. L. Marketing contemporâneo. São Paulo: Cengage Learning, 2009. COBRA, M. H. N. Marketing de turismo. São Paulo: Cobra Editora, 2005.

KOTLER, P. Administração de marketing: a edição do novo milênio. 10. ed. São Paulo: Prentice Hall, 2000.

. Administração de marketing: análise, planejamento, implementação e controle. 5. ed. São Paulo: Atlas, 1998.

OLIVEIRA, R. Ações de marketing nas pequenas e médias empresas do setor hoteleiro em Aracaju. In: CONGRESSO DE CIÊNCIAS DA COMUNICAÇÃO DA REGIÃO NORDESTE, 14., 2012, Recife. Resumos... Disponível em: <http://www.intercom.org.br/papers/regionais/ nordeste2012/resumos/R32-1110-1.pdf>. Acesso em: 4 jul. 2013.

SANTOS, A. V. dos; SANTOS, M. T. dos. Marketing turístico: curso técnico em hospedagem. 2011. Disponível em: < http://redeetec.mec.gov.br/images/stories/pdf/eixo_hosp_lazer/061112_ marketing_tur.pdf $>$. Acesso em: 25 jun. 2013.

Submetido em 14 de janeiro de 2014.

Aprovado em 10 de março de 2014. 